\title{
Middle Phase Electrochemistry of Two Pentacyano(L)Ferrates(II)
}

\author{
Daniela Bala, Petronia Dasu, and Constantin Mihailciuc* \\ Physical Chemistry Department, Faculty of Chemistry, University of Bucharest, \\ Regina Elisabeta 4-12, Bucharest RO-030018, Romania
}

RECEIVED NOVEMBER 1, 2011; REVISED OCTOBER 3, 2012; ACCEPTED OCTOBER 18, 2012

\begin{abstract}
The electrochemical behaviour of two water soluble redox species (pentacyano(L)ferrate(II) complexes, where $\mathrm{L}$ is $4,4^{\prime}$-bipyridine and ammonia), belonging to cyanoferrate(II) series, was investigated by using cyclic voltammetry (CV) technique in a "middle phase microemulsion" (MPME). The microemulsion (ME) is formed between water and toluene, by using, besides the redox species, sodium dodecyl sulphate as surfactant, 1-butanol as cosurfactant and sodium chloride as supporting electrolyte. Three different three-electrode configuration arrangements were used. In each case reversible behaviour for both species was obtained. Different behaviour was found in "middle phase" for the two investigated electroactive species based on the presence of the sixth ligand (coligand). The coligand determines, on one hand, different electronic influence on the electron transfer reaction at Pt working electrode and, on the other hand, specific interaction with the "microscopic organic phase" from "middle phase". This paper demonstrates, based on Randles-Sevcik equation, that $\left[\mathrm{Fe}(\mathrm{CN})_{5}\left(4,4^{\prime}-\text { bpy }\right)\right]^{3-}$ is distributed between the "water phase" and "microscopic aqueous phase" rather in latter phase. For $\left[\mathrm{Fe}(\mathrm{CN})_{5}\left(\mathrm{NH}_{3}\right)\right]^{3-}$, its distribution is similar with that of the common hexacyanoferrate(III) or hexacyanoferrate(II). The CV study of the two different electroactive species illustrates an almost reversible behaviour both in "middle phase" and "water phase". (doi: 10.5562/cca1999)
\end{abstract}

Keywords: middle phase microemulsion, cyclic voltammetry, active working electrode area

\section{INTRODUCTION}

A microemulsion (ME) is formed spontaneously from a system containing water, organic solvent, surfactant, and often cosurfactant, in the presence of an adequate electrolyte. MEs have low viscosity and are thermodynamically very stable. ${ }^{1}$ There are two types of microemulsions, oil-in-water $(\mathrm{o} / \mathrm{w}$, when the surfactant is strongly hydrophilic) and water-in-oil (w/o, when the surfactant is strongly lipophilic). The $\mathrm{o} / \mathrm{w}$ is a dispersion of a water-immiscible liquid (oil) in an aqueous phase and w/o is a dispersion of an aqueous solution in a water-immiscible liquid (oil). Modifying some emulsification conditions can lead to a microemulsion change from $\mathrm{o} / \mathrm{w}$ to $\mathrm{w} / \mathrm{o}$ and vice versa. The surfactant properties determine the morphology of ME. This can provide possible applications in analytical systems, phasetransfer redox reaction, model membrane systems in catalysis, solubilization media, etc. Depending on the appropriate balance between hydrophilicity and lipophilicity (HLB) of a surfactant in the system, moderated by cosurfactant and electrolyte (salt) concentration, microemulsion reveals a bicontinuous structure and a dynamic existence known as "middle phase microemul- sion" (MPME). ${ }^{2-5}$ The aqueous and the organic phases form the so-called bicontinuous structure, ${ }^{6,7}$ consisting of "microscopic aqueous phases or tubes" and "microscopic organic phases or tubes", these two different phases alternating on a microscopic scale, each of them being locally continuous. ${ }^{8}$ It is described as a network of water tubes in an oil matrix or a network of oil tubes in a water matrix. The ionic conductivity of the MPME is maintained either by the continuous "microscopic aqueous phase" or by "microscopic organic phase", at least one of them containing the indifferent electrolyte ions and the electroactive species depending on their HLB (as to be solved in one or another "microscopic phase"). Several electrochemical techniques such as cyclic voltammetry (CV), differential pulse voltammetry (DPV), rotation disk electrode voltammetry (RDEV) and chronocoulometry (CC), electrical conductivity and so on, involving an electroactive compound and an appropriate electrode, have been used for the study of physico-chemical properties of these systems. In the present work, it was chosen a MPME obtained by using wellknown standard recipe ${ }^{9}$ from an initial system consisting of water, toluene, sodium dodecyl sulphate as surfactant, 1-butanol as cosurfactant, and sodium chloride

\footnotetext{
* Author to whom correspondence should be addressed. (E-mail: cmpaul@gw-chimie.math.unibuc.ro)
} 
as supporting electrolyte. This system leads to three macroscopically separated phases (from the upper to the lower phase): a "toluene (organic) phase", a "middle phase" (MP) and a "water (aqueous) phase" (W) which is saline in fact, due to the used sodium chloride. The presence of a redox species, such as ferricyanide or ferrocyanide, in an appropriate concentration, does not modify the phase diagram of the system. The redox species can be found both in the "water phase" and in the "microscopic aqueous phase" from the "middle phase" due to its solubility in the water existing inside the MPME. In this case the electrochemistry of a particular cyanoferrate may be studied even in the "middle phase", even if this "middle phase" is highly dynamic and even if the surface of the working electrode is, simultaneously in time but alternatively in space, in direct contact with the "organic film" and with "aqueous film" (which constitutes the "middle phase") in a statistical fashion and dynamic way. ${ }^{10}$ The electroactive species is chosen in order to have a simple, reversible electrochemistry, high solubility in water and low solubility in toluene (the electroactive species being very hydrophilic) or, on the contrary, low solubility in water and high solubility in toluene (the electroactive species being very lipophilic). In addition, both redox forms are sufficiently soluble in water in contrast with other redox couples in which electroactive species can be oil soluble or both in water and organic phases. ${ }^{11,12}$ Generally speaking, the occurrence of the electrode reaction in "middle phase" might be influenced by the HLB of electrode active surface, of redox species initially used (by the presence of the coligand), and of countercation. All these factors can decide the repartition of the electroactive species between the two aqueous phases. Even the charge of the electroactive complex ion might play a part in its existence in the "microscopic aqueous phase". ${ }^{13}$ The investigation of MPMEs electrochemical behaviour can bring contributions to the fundamental study of organized systems with surfactants. In this paper two complexes, $\mathrm{Na}_{3}\left[\mathrm{Fe}(\mathrm{CN})_{5}(4,4\right.$ '-bpy $\left.)\right]$ and $\mathrm{Na}_{3}\left[\mathrm{Fe}(\mathrm{CN})_{5}\left(\mathrm{NH}_{3}\right)\right]$, were studied by $\mathrm{CV}$ technique both in "middle phase" and "water phase". We found that both electroactive species give rise to fast electrode reactions at the $\mathrm{Pt}$ working electrode. Their half-wave and standard electrode potentials were determined and they are different depending on the electronic effects of the coligand. A comparison with the electrochemical behaviour of typical hexacyanoferrate(II) is also made.

\section{EXPERIMENTAL}

\section{Apparatus}

Electrochemical experiments were carried out using the potentiostat-galvanostat system AutoLab PGStat 12, controlled by GPES (General Purpose Electrochemical
System) electrochemical interface for Windows (version 4.9.007). Three electrodes in one-compartment cell (10 $\mathrm{mL}$ ) were used in all experiments. Platinum disk electrode (Metrohm, $3 \mathrm{~mm}$ in diameter) served as working electrode (WE). The counter electrode (CE) was a platinum disk (Metrohm, $3 \mathrm{~mm}$ in diameter) electrode too. All potentials were measured and are referred to the $\mathrm{Ag} \mid \mathrm{AgCl}\left(c(\mathrm{KCl})=3 \mathrm{~mol} \mathrm{dm}^{-3}\right)$ electrode used as reference (RE).

\section{Measurements}

All measurements were carried out at room temperature with no stirring and no inert gas purged. Three different positions of the three-electrode configuration were used: all electrodes in "middle phase" (denoted as MP), all electrodes in "water phase" (denoted as W) and WE and $\mathrm{CE}$ in "middle phase" and the RE in "water phase" (denoted as MP-W). The scan rate range used was from 10 to $100 \mathrm{mV} \mathrm{s}^{-1}$, with an increment of 10 and the domain potential from $0.0 \mathrm{~V}$ to $0.6 \mathrm{~V}$, with first scan in the anodic direction. Microemulsions were prepared as indicated in a standard recipe, ${ }^{9}$ the typical content of the three phase system being: water (4.68 g), toluene (4.625 g), $\mathrm{NaCl}(0.30 \mathrm{~g})$, sodium dodecyl sulfate $(0.199 \mathrm{~g}), 1$-butanol $(0.396 \mathrm{~g})$, and appropriate amount of $\mathrm{Na}_{3}\left[\mathrm{Fe}(\mathrm{CN})_{5^{-}}\right.$ $\left(4,4^{\prime}-\right.$ bpy $\left.)\right]$ or $\mathrm{Na}_{3}\left[\mathrm{Fe}(\mathrm{CN})_{5}\left(\mathrm{NH}_{3}\right)\right]$ calculated for concentration of $1 \mathrm{mmol} \mathrm{dm}^{-3}$ referred to the amount of water. The sodium chloride $\left(1.1 \mathrm{~mol} \mathrm{dm}^{-3}\right.$ solution, calculated to the amount of water) plays the indifferent electrolyte role both in the "microscopic aqueous phase" and "water phase".

\section{Chemicals}

Toluene and 1-butanol (both from Sigma) were used without further purification, the water was doubly distilled. $\mathrm{NaCl}$ (Fluka) and sodium dodecyl sulphate (Fluka) were also used without further purification and they all were analytical reagent grade. The two electroactive reagents, $\mathrm{Na}_{3}\left[\mathrm{Fe}(\mathrm{CN})_{5}\left(4,44^{\prime}-\right.\right.$ bpy $\left.)\right]$ and $\mathrm{Na}_{3}\left[\mathrm{Fe}-(\mathrm{CN})_{5}\left(\mathrm{NH}_{3}\right)\right]$, were prepared in the Inorganic Chemistry Department of our Faculty of Chemistry. ${ }^{14,15}$ Before modification, the platinum electrode surface was polished with alumina $(0.05 \mu \mathrm{m})$ slurry on a polishing pad, washed with distilled water and sonicated for 3 minutes in doubly distilled water, then again washed with doubly distilled water.

\section{RESULTS AND DISCUSSION}

The two studied complex ions originate from $\mathrm{Na}_{3}[\mathrm{Fe}-$ $(\mathrm{CN})_{5}\left(4,4^{\prime}-\right.$ bpy $\left.)\right]$ and $\mathrm{Na}_{3}\left[\mathrm{Fe}(\mathrm{CN})_{5}\left(\mathrm{NH}_{3}\right)\right]$. The common counterion $\left(\mathrm{Na}^{+}\right)$has more or less the same influence on the general $\mathrm{HLB}$ as $\mathrm{K}^{+}$counterion used in a previous study $^{13}$ on the MPME electrochemistry. In both cases 
Table 1. Regression equations and $R^{2}$ (regression coefficient) for $\left[\mathrm{Fe}(\mathrm{CN})_{5}\left(4,4^{\prime}-\mathrm{bpy}\right)\right]^{3-}$ and $\left[\mathrm{Fe}(\mathrm{CN})_{5}\left(\mathrm{NH}_{3}\right)\right]^{3-}$ in "middle phase" (MP) and water (W)

\begin{tabular}{ccc}
\hline Electroactive species & $\begin{array}{c}\text { Regression equation } \\
\text { for } \ln \left(I_{\mathrm{pa}} / \mathrm{A}\right) v s . \ln \left(v / \mathrm{Vs}^{-1}\right)\end{array}$ & $R^{2}$ \\
\hline$\left[\mathrm{Fe}(\mathrm{CN})_{5}\left(4,4^{\prime}-\mathrm{bpy}\right)\right]^{3-}$ & $\ln I_{\mathrm{pa}, \mathrm{MP}}=-11.66+0.64 \ln v$ & 0.9974 \\
& $I_{\mathrm{pa}, \mathrm{W}}=2.15 \cdot 10^{-7}+4.02 \cdot 10^{-6} v^{1 / 2}$ & 0.9931 \\
& $\ln I_{\mathrm{pa}, \mathrm{MP}}=-11.88+0.52 \ln v$ & 0.9976 \\
& $I_{\mathrm{pa}, \mathrm{W}}=2.48 \cdot 10^{-7}+1.71 \cdot 10^{-5} v^{1 / 2}$ & 0.9973 \\
\hline
\end{tabular}
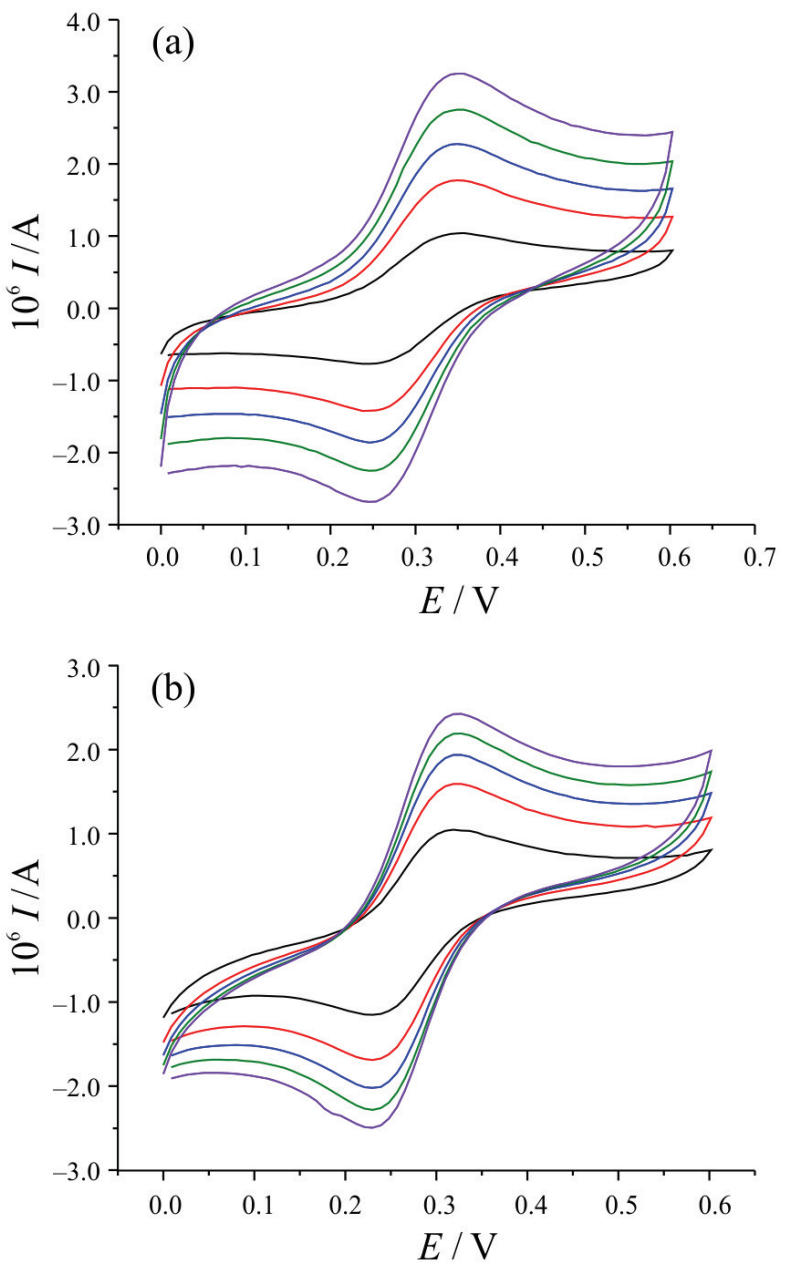

Figure 1. The cyclic voltamograms of $\mathrm{Na}_{3}\left[\mathrm{Fe}(\mathrm{CN})_{5}\left(4,44^{\prime}\right.\right.$ bpy)] (a) and $\mathrm{Na}_{3}\left[\mathrm{Fe}(\mathrm{CN})_{5}\left(\mathrm{NH}_{3}\right)\right]$ (b) in "middle phase" at scan rates from 20 to $100 \mathrm{mV} \mathrm{s}^{-1}$ (with an increment of 20) for initial concentration of $1 \mathrm{mmol} \mathrm{dm}{ }^{-3}$ referred to initial water amount.

this type of countercation does not influence the distribution of the electroactive species between the two aqueous phases. The most important influence might be brought by the presence of the different coligand, of course, 4,4'-bpy being more lipophilic/less hydrophilic than $\mathrm{NH}_{3}$.

In Figures 1a $\left(\left[\mathrm{Fe}(\mathrm{CN})_{5}\left(4,4^{\prime}-\mathrm{bpy}\right)\right]^{3-}\right)$ and $1 \mathrm{~b}([\mathrm{Fe}-$ $\left.\left.(\mathrm{CN})_{5}\left(\mathrm{NH}_{3}\right)\right]^{3-}\right)$ cyclic voltammetric behaviours, in the "middle phase", for scan rates 20, 40, 60, 80 and 100 $\mathrm{mV} \mathrm{s}^{-1}$, are presented. In the scan rate range investigated, one can notice an almost reversible behaviour of both redox couples.

For the corresponding cyclic voltamograms in Figures $1 \mathrm{a}$ and $1 \mathrm{~b}$, respectively, plotting the $\ln I_{\mathrm{pa}} v s . \ln v$ for $\left[\mathrm{Fe}(\mathrm{CN})_{5}\left(4,4^{\prime}-\text { bpy) }\right]^{2-}\right.$ (Figure $\left.2 \mathrm{a}\right)$ and $\left[\mathrm{Fe}(\mathrm{CN})_{5}\right.$ $\left.\left(\mathrm{NH}_{3}\right)\right]^{2-}$ (Figure 2b), respectively, straight lines are obtained with very good regression coefficients, $R^{2}$ (see Table 1). For the latter redox couple, the slope is 0.52 , very close to the theoretical one $(0.50)$ for a diffusional electroactive species (see Figure $2 \mathrm{~b}$ ). The plot $I_{\mathrm{pa}} v s . v^{1 / 2}$ is linear, the straight line forced to pass through the origin has $R^{2}=0.9969$ and a slope of $6.59 \cdot 10^{-6}$. The same plot, with both parameters variable, leads to a straight line having $R^{2}=0.9971$, the ordinate intercept is $2.26 \cdot 10^{-8}$, and the slope $6.69 \cdot 10^{-6}$. One can observe a very small difference between the two slopes. For the former redox couple, the slope of the plot $\ln I_{\mathrm{pa}} v s . \ln v$ is different, worthing 0.64. The two plots, $I_{\mathrm{pa}} v s . v^{1 / 2}$, forced or not to pass through origin, lead to the following equations: $I_{\mathrm{pa}, \mathrm{MP}}=0+5.90 \cdot 10^{-6} v^{1 / 2}\left(R^{2}=0.9639\right)$ and $I_{\mathrm{pa}, \mathrm{MP}}=-3.02 \cdot 10^{-7}+7.13 \cdot 10^{-6} v^{1 / 2}\left(R^{2}=0.9963\right)$, respectively. It can be seen the large difference between the two slopes. In this case, it is very possible for the electroactive species to participate to the electrode reaction both as diffusional species (mainly) and adsorbed species (secondary), due to the existence of the more lipophilic coligand. Taking into account the appearance of a unique anodic peak (as well as a unique cathodic peak), the adsorption is, in fact, very weak. These data are confirmed by the study made in "water phase" (see Table 1 for the plots $I_{\mathrm{pa}} v s . v^{1 / 2}$ ).

For small scan rates, the peak currents ratios, $\left|I_{\mathrm{pc}} / I_{\mathrm{pa}}\right|$, are, in some extent, greater than unity due to the increased interactions between the cyanoferrate(II) ion with the negatively charged interface (with the negative end toward the aqueous phase) formed between the two microscopic phases in "middle phase microemulsion". At all scan rates used, the anodic and cathodic peak potentials seem to be in a very small degree variable (around the following values $E_{\mathrm{pa}}=0.339 \mathrm{~V}$ and $\left.E_{\mathrm{pc}}=0.259 \mathrm{~V}\right)$ for $\left[\mathrm{Fe}(\mathrm{CN})_{5}\left(4,4^{\prime}-\right.\right.$ bpy $)]^{2-} /\left[\mathrm{Fe}(\mathrm{CN})_{5}\left(4,4^{\prime}-\text { bpy }\right)\right]^{3-}$ and are almost constant, $E_{\mathrm{pa}}=0.314 \mathrm{~V}$ and $E_{\mathrm{pc}}=0.240 \mathrm{~V}$ for $\left[\mathrm{Fe}(\mathrm{CN})_{5}\left(\mathrm{NH}_{3}\right)\right]^{2-}$ 
Table 2. Significant $C V$ data for $\Delta E_{\mathrm{p}} / \mathrm{mV}, E_{1 / 2} / \mathrm{mV}$ and $\left|I_{\mathrm{pc}} / I_{\mathrm{pa}}\right|$ (at scan rates of 10 and $100 \mathrm{mV} \mathrm{s}^{-1}$ ) for $\left[\mathrm{Fe}(\mathrm{CN})_{5}\left(4,4^{\prime}-\mathrm{bpy}\right)\right]^{3-}$ and $\left[\mathrm{Fe}(\mathrm{CN})_{5}\left(\mathrm{NH}_{3}\right)\right]^{3-}$ in "middle phase"

\begin{tabular}{|c|c|c|c|c|c|c|}
\hline & \multicolumn{2}{|c|}{$\Delta E_{\mathrm{p}} / \mathrm{mV}$} & \multicolumn{2}{|c|}{$E_{1 / 2} / \mathrm{mV}$} & \multicolumn{2}{|c|}{$\left|I_{\mathrm{pc}} / I_{\mathrm{pa}}\right|$} \\
\hline scan rate, $v / \mathrm{mV} \mathrm{s}^{-1}$ & 10 & 100 & 10 & 100 & 10 & 100 \\
\hline$\left[\mathrm{Fe}(\mathrm{CN})_{5}\left(4,4^{\prime}-\mathrm{bpy}\right)\right]^{3-}$ & 71 & 79 & 298 & 298 & 1.01 & 0.94 \\
\hline$\left[\mathrm{Fe}(\mathrm{CN})_{5}\left(\mathrm{NH}_{3}\right)\right]^{3-}$ & 71 & 79 & 275 & 275 & 1.07 & 1.11 \\
\hline
\end{tabular}

$/\left[\mathrm{Fe}(\mathrm{CN})_{5}\left(\mathrm{NH}_{3}\right)\right]^{3-}$ redox couple, respectively. As a consequence, the peak separation is also constant in the scan range used to study the behaviour of the two complex ions having the following values for $\left[\mathrm{Fe}(\mathrm{CN})_{5}\left(4,4^{\prime}-\right.\right.$ bpy) $]^{2-} \Delta E_{\mathrm{p}} \cong 0.080 \mathrm{~V}$ and for $\left[\mathrm{Fe}(\mathrm{CN})_{5}\left(\mathrm{NH}_{3}\right)\right]^{2-} \Delta E_{\mathrm{p}} \cong$ $0.074 \mathrm{~V}$, not too different from the theoretical value of $59 \mathrm{mV}$, perhaps influenced by an uncompensated ohmic drop appearing in MPME (see Table 2). This uncompensated ohmic drop enlarges the peak separation. ${ }^{16}$ It can appear from the discontinuities introduced on the WE surface due to the fact that the active surface exposed by the WE in the "middle phase" as electrode reaction scene, is alternatively in contact with conductive "microscopic aqueous phase" and nonconductive "microscopic organic phase".

As concerns the electrode reaction, which is the same, at the WE when all electrodes are immersed in "water phase", the peak current ratios, $\left|I_{\mathrm{pc}} / I_{\mathrm{pa}}\right|$, behaves in the same way as indicated above for all electrodes in "middle phase". One can explain this by the following supposition: the repartition of cyanoferrate(II) in MPME is probably (even if in a small extent) more hindered than that of cyanoferrate(III). The main cause is the higher negative charge of the former complex ion and of the negative charge of the water side of the interface between the "microscopic aqueous phase" and "microscopic organic phase". So it seems to be reasonable as, besides the major influence of the HLB, to take into account the dependence upon the charge of the complex ions, as demonstrated in a previous study. ${ }^{13}$ For that particular reason, unequal concentrations of each redox species of the redox couple in the two aqueous phases could result. Regarding the two complexes studied in this paper, the repartition of $\left[\mathrm{Fe}(\mathrm{CN})_{5}\left(4,4^{\prime}-\text { bpy }\right)\right]^{2-}$ in MPME vs. "water phase" seems to be more favoured in comparison to that of $\left[\mathrm{Fe}(\mathrm{CN})_{5}\left(\mathrm{NH}_{3}\right)\right]^{2-}$. The main cause is the more favourable lipophilicity vs. hydrophilicity of 4,4'-bpy in comparison with $\mathrm{NH}_{3}$. This results in higher peak currents recorded for the former complex ion than for the latter (see Figures 1a and 1b).

The half-peak potentials, $E_{1 / 2}$, are $0.299 \mathrm{~V}$ for $\left[\mathrm{Fe}(\mathrm{CN})_{5}\left(4,4^{\prime}-\text { bpy }\right)\right]^{2-} /\left[\mathrm{Fe}(\mathrm{CN})_{5}\left(4,4^{\prime}-\text { bpy }\right)\right]^{3-}$ and 0.277 $\mathrm{V}$ for $\left[\mathrm{Fe}(\mathrm{CN})_{5}\left(\mathrm{NH}_{3}\right)\right]^{2-} /\left[\mathrm{Fe}(\mathrm{CN})_{5}\left(\mathrm{NH}_{3}\right)\right]^{3-}$ so that the former complex ions is harder to be oxidized than the
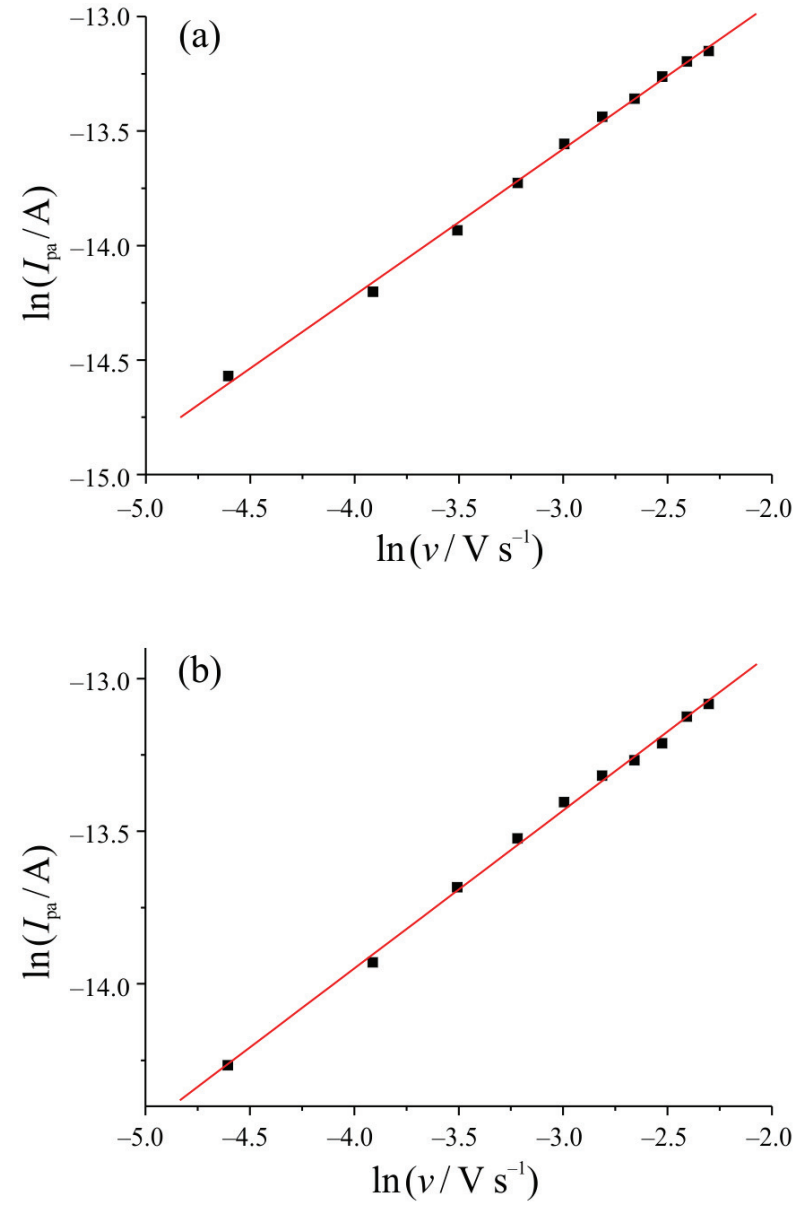

Figure 2. The dependences $\ln I_{\mathrm{pa}} v s . \ln v$ for the forward/direct peaks in the "middle phase" for $\mathrm{Na}_{3}\left[\mathrm{Fe}(\mathrm{CN})_{5}\left(4,44^{\prime}-\right.\right.$ bpy) $]$ (a) and $\mathrm{Na}_{3}\left[\mathrm{Fe}(\mathrm{CN})_{5}\left(\mathrm{NH}_{3}\right)\right]$ (b) at scan rates from 10 to $100 \mathrm{mV} \mathrm{s}^{-1}$ for initial concentration of $1 \mathrm{mmol} \mathrm{dm}{ }^{-3}$ referred to initial water amount.

latter. This conclusion remains valid in all three different three-electrode configuration arrangements.

All the diagnostic criteria indicate almost reversible electrochemical behaviour of the electrode reaction at the WE operating in MPME in both studied cases.

The same almost reversible electrochemical behaviour was seen for cyclic voltammetric studies performed by using the other two three-electrode configuration arrangements. All significant results, consisting in $\Delta E_{\mathrm{p}}, \quad E_{1 / 2}, \quad\left|I_{\mathrm{pc}} / I_{\mathrm{pa}}\right|, \quad$ for the two complex pentacyano(L)ferrates(II), are listed in Table 3.

The behaviour of the two complex ions, $\left[\mathrm{Fe}(\mathrm{CN})_{5}\left(4,4^{\prime}-\text { bpy }\right)\right]^{3-}$ and $\left[\mathrm{Fe}(\mathrm{CN})_{5}\left(\mathrm{NH}_{3}\right)\right]^{3-}$, in $\mathrm{ME}$ in three different cases: case MP in which all three electrodes are immersed in "middle phase" (Figures 3a and $3 \mathrm{~b}$, curves A), case $\mathrm{W}$ with all electrodes immersed in "water phase" (Figures 3a and 3b, curves B) and case MP-W with the WE and CE in "middle phase" and the RE moved in "water phase" (Figures 3a and 3b, curves C) was studied at different scan rates. 
Table 3. Significant CV numerical data for $\Delta E_{\mathrm{p}} / \mathrm{mV}$ (mean value), $E_{1 / 2} / \mathrm{mV}$ (mean value), $I_{\mathrm{pa}, \mathrm{MP}}: I_{\mathrm{pa}, \mathrm{W}}$ and $I_{\mathrm{pa}, \mathrm{MP}}: I_{\mathrm{pa}, \mathrm{MP}-\mathrm{W}}($ at scan rate of $\left.20 \mathrm{mVs}^{-1}\right)$ for $\left[\mathrm{Fe}(\mathrm{CN})_{5}\left(4,4^{\prime}-\mathrm{bpy}\right)\right]^{3-}$ and $\left[\mathrm{Fe}(\mathrm{CN})_{5}\left(\mathrm{NH}_{3}\right)\right]^{3-}$ with all three electrodes in "middle phase" (MP), with WE and $\mathrm{CE}$ in "middle phase" and RE in "water phase" (MP-W) and with all three electrodes in "water phase" (W)

\begin{tabular}{|c|c|c|c|c|c|c|c|c|}
\hline \multirow{2}{*}{ Electroactive species } & \multicolumn{2}{|c|}{ MP } & \multicolumn{2}{|c|}{ MP-W } & \multicolumn{2}{|c|}{ W } & \multicolumn{2}{|c|}{ peak currents ratios } \\
\hline & $\Delta E_{\mathrm{p}} / \mathrm{mV}$ & $E_{1 / 2} / \mathrm{mV}$ & $\Delta E_{\mathrm{p}} / \mathrm{mV}$ & $E_{1 / 2} / \mathrm{mV}$ & $\Delta E_{\mathrm{p}} / \mathrm{mV}$ & $E_{1 / 2} / \mathrm{mV}$ & $I_{\mathrm{pa}, \mathrm{MP}}: I_{\mathrm{pa}, \mathrm{W}}$ & $I_{\mathrm{pa}, \mathrm{MP}}: I_{\mathrm{pa}, \mathrm{MP}-\mathrm{W}}$ \\
\hline$\left[\mathrm{Fe}(\mathrm{CN})_{5}\left(4,4^{\prime}-\mathrm{bpy}\right)\right]^{3-}$ & 80 & 298 & 79 & 295 & 86 & 290 & 0.94 & 0.97 \\
\hline$\left[\mathrm{Fe}(\mathrm{CN})_{5}\left(\mathrm{NH}_{3}\right)\right]^{3-}$ & 74 & 275 & 80 & 270 & 79 & 275 & 0.32 & 1.45 \\
\hline
\end{tabular}
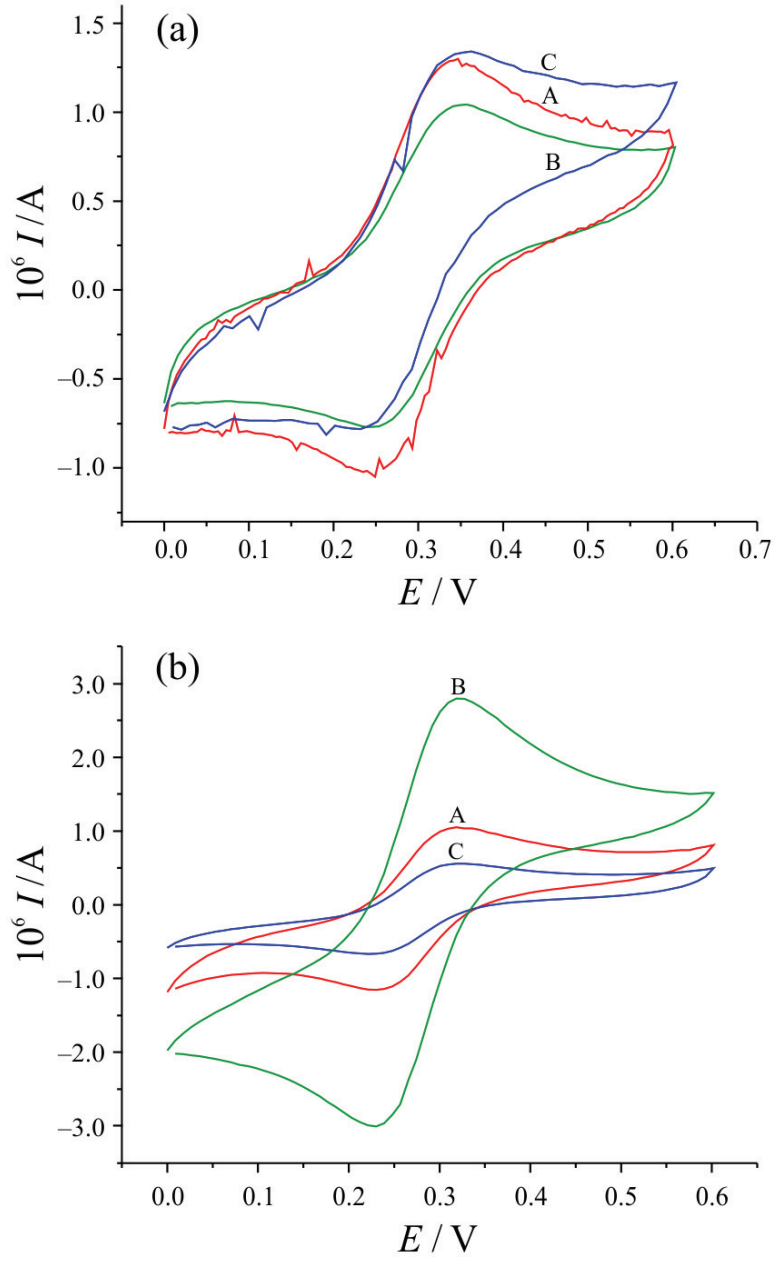

Figure 3. The cyclic voltamograms of $\mathrm{Na}_{3}\left[\mathrm{Fe}(\mathrm{CN})_{5}\left(4,4^{\prime}-\right.\right.$ bpy)] (a) and $\mathrm{Na}_{3}\left[\mathrm{Fe}(\mathrm{CN})_{5}\left(\mathrm{NH}_{3}\right)\right]$ (b) with all electrodes in "middle phase" (A), with all electrodes in "water phase" (B) and with WE and CE in "middle phase" and RE in "water phase" (C) at $v=20 \mathrm{mV} \mathrm{s}^{-1}$ for initial concentration of $1 \mathrm{mmol}$ $\mathrm{dm}^{-3}$ referred to initial water amount.

The displacement of the RE from the "middle phase" to the "water phase" does not lead to a significant difference concerning both the shape and the main electrochemical data (presented in Table 3) either for $\left[\mathrm{Fe}(\mathrm{CN})_{5}\left(4,4^{\prime}-\mathrm{bpy}\right)\right]^{3-}$ (curves $\mathrm{A}$ and $\mathrm{C}$ in Figure $3 \mathrm{a}$ ) or for $\left[\mathrm{Fe}(\mathrm{CN})_{5}\left(\mathrm{NH}_{3}\right)\right]^{3-}$ (curves $\mathrm{A}$ and $\mathrm{C}$ in Figure $3 \mathrm{~b}$ ). Both the peak potentials and the peak currents are more or less the same for each complex ion considered above; for the former there is a small difference in the peak currents and for the latter they have the same shape but shifted on the current axis. However, when all three electrodes are placed inside the "water phase", a very different behaviour was recorded between the two investigated species, as can be seen from curves B in Figures $3 \mathrm{a}$ and $3 \mathrm{~b}$. This could be assigned to the presence of the coligand which influences the concentrations in the two aqueous phases in different manner by its own HLB.

The comparison between recorded cyclic voltamograms reveals the influence of the water insoluble 4,4'-bipyridine as ligand in the complex. The cyclic voltamograms obtained to the WE placed in "middle phase" are, more or less, identical in shape excepting a small influence of the capacitive current after the two peaks (anodic and cathodic) due to the different positions of the RE. Concerning the peak currents and the peak potentials, as can be seen from the curves $\mathrm{A}$ and $\mathrm{C}$ in Figure 3a, they are the same. Surprisingly, the cyclic voltamograms recorded with all three electrodes in "water phase", though of the same shape and having the same peak potentials, have lower anodic peak current than expected (curve B in Figure 3a).

In the case of ammonia as ligand in the complex the cyclic voltamograms obtained to the WE placed in "middle phase" have relatively identical shape and almost the same peak currents and peak potentials (curves $\mathrm{A}$ and $\mathrm{C}$ in Figure $3 \mathrm{~b}$ ). Similarly with common hexacyanoferrates(II) and(III), the cyclic voltamograms recorded with all three electrodes in "water phase", though of the same shape and having the same peak potentials, have higher anodic peak current than expected (curve B in Figure 3b).

Taking into account the ratio between the volumes of "water phase" and "organic phase" before and after the formation of the "three-phase system", which is almost unity, one can assume that the surface of the WE in contact with "microscopic aqueous phase" and the surface of the WE in contact with "microscopic organic phase" are close enough to half of the entire WE surface. In fact, in the phase diagram ${ }^{17,18}$ there is, more or less, only a little shift of the point denoting the threephase system. So that, the electrode reaction is confined to almost one half of the WE surface. On the contrary in 
"water phase" the entire WE surface is the stage of the electrode reaction. For equal electroactive species concentrations in both "water phase" and "microscopic aqueous phase", as could be considered in the first instance, the peak currents with the WE in "water phase" has to be double in comparison with those obtained with the WE in "middle phase". Considering Randles-Sevcik well-known equation, it results that:

$$
\frac{\left(I_{\mathrm{p}}\right)_{\mathrm{MP}}}{\left(I_{\mathrm{p}}\right)_{\mathrm{W}}}=\frac{A_{\mathrm{MP}}}{A_{\mathrm{W}}} \frac{D_{\mathrm{MP}}^{1 / 2} c_{\mathrm{MP}}}{D_{\mathrm{W}}^{1 / 2} c_{\mathrm{W}}}
$$

where $\mathrm{A}$ is the active working electrode area, $D$ is the diffusion coefficient and $c$ is the concentration of electroactive species. In other words:

$$
\frac{A_{\mathrm{MP}}}{A_{\mathrm{W}}} \frac{D_{\mathrm{MP}}^{1 / 2} c_{\mathrm{MP}}}{D_{\mathrm{W}}^{1 / 2} c_{\mathrm{W}}}=\frac{b_{\mathrm{MP}}}{b_{\mathrm{W}}}
$$

where $b_{\mathrm{MP}}$ and $b_{\mathrm{W}}$ are the slopes of the plots $I_{\mathrm{pa}} v s . v^{1 / 2}$ in "middle phase" and in "water phase".

For the supposition made above $\left(2 A_{\mathrm{MP}}=A_{\mathrm{W}}\right)$, the Eq. (1) leads to:

$$
\frac{\left(I_{\mathrm{p}}\right)_{\mathrm{MP}}}{\left(I_{\mathrm{p}}\right)_{\mathrm{W}}}=\frac{1}{2} \frac{D_{\mathrm{MP}}^{1 / 2} c_{\mathrm{MP}}}{D_{\mathrm{W}}^{1 / 2} c_{\mathrm{W}}}
$$

and Eq. (2) becomes:

$$
\frac{1}{2} \frac{D_{\mathrm{MP}}^{1 / 2} c_{\mathrm{MP}}}{D_{\mathrm{W}}^{1 / 2} c_{\mathrm{W}}}=\frac{b_{\mathrm{MP}}}{b_{\mathrm{W}}}
$$

for a given sweep rate. The values for $b_{\mathrm{MP}}$ and $b_{\mathrm{W}}$ could be calculated from the plot $I_{\mathrm{pa}} v s . v^{1 / 2}$.

Considering the active working electrode area as being equal to that when the WE is positioned inside the "water phase", the ratio

$$
\frac{D_{\mathrm{MP}}^{1 / 2} c_{\mathrm{MP}}}{D_{\mathrm{W}}^{1 / 2} c_{\mathrm{W}}},
$$

calculated by using the necessary slopes for the system with $\left[\mathrm{Fe}(\mathrm{CN})_{5}\left(4,4^{\prime}-\mathrm{bpy}\right)\right]^{2-}$, is equal to 1.77 . This ratio is larger than unity even in the supposition that the WE surface is in direct contact only with the "microscopic aqueous phase". But in fact only a fraction of this surface is the stage of the electrode reaction in "middle phase" so that, in the real case, the above ratio is even larger. It results that, even for equal diffusion coefficients, there is an accumulation of the $\left[\mathrm{Fe}(\mathrm{CN})_{5}\left(4,4^{\prime}-\mathrm{bpy}\right)\right]^{3-}$ in "microscopic aqueous phase" from "middle phase" vs. "water phase". This accumulation/concentration is, of course, favoured by the presence of 4,4'-bipyridine as ligand in complex. For $2 A_{\mathrm{MP}}=A_{\mathrm{W}}$ the above ratio increased to 3.54. Of course, the assumption of equal diffusion coefficients is not entirely correct, as it was already found in different other works. In fact, in "middle phase" the diffusion coefficient is even smaller than in "water phase". As a consequence, a more concentrated solution in electroactive species $\left[\mathrm{Fe}(\mathrm{CN})_{5}\left(4,4^{\prime}-\mathrm{bpy}\right)\right]^{3-}$ is obtained in "microscopic aqueous phase" from "middle phase".

The same comparison, made above for $\left[\mathrm{Fe}(\mathrm{CN})_{5^{-}}\right.$ $\left(4,4^{\prime}-\right.$ bpy $\left.)\right]^{3-}$, is given for $\left[\mathrm{Fe}(\mathrm{CN})_{5}\left(\mathrm{NH}_{3}\right)\right]^{3-}$ in Figure $3 \mathrm{~b}$. In this case the cyclic voltamogram obtained in "water phase" is much more extended on the current dimension than that recorded with the WE positioned in "middle phase". Considering the active working electrode area as being equal to that when the WE is positioned inside the "water phase", the ratio

$$
\frac{D_{M P}^{1 / 2} c_{M P}}{D_{W}^{1 / 2} c_{W}},
$$

calculated by using the necessary slopes, is equal to 0.39 . This ratio is smaller than unity and it remains smaller than unity as long as the WE surface used for driven the electrode reaction is not smaller than $2 / 5$ from the entire WE surface. For $2 A_{\mathrm{MP}}=A_{\mathrm{W}}$ the above ratio increased to 0.78 . Taking into account the nature of the sixth ligand, $\mathrm{NH}_{3}$, in the complex $\left[\mathrm{Fe}(\mathrm{CN})_{5}\right.$ $\left.\left(\mathrm{NH}_{3}\right)\right]^{3-}$, one can suppose equal concentrations of the complex in both "microscopic aqueous phase" and "water phase". Further, accepting a suitable presumption, one can estimate either the diffusion coefficient or the WE area confined to the occurrence of the electrode reaction. As a matter of fact, the hypothesis of equal diffusion coefficients for electroactive species in both aqueous parts of the three-phase system is in contradiction with the fact that in "middle phase" the diffusion coefficient is even smaller than in "water phase". So it remains only the hypothesis of equal concentrations of the electroactive species in the two parts aforementioned. Along with the $2 A_{\mathrm{MP}}=A_{\mathrm{W}}$ condition to have no shift in the phase diagram ${ }^{11}$ of the three-phase system, one can estimate the ratio $D_{\mathrm{MP}}^{1 / 2}: D_{\mathrm{W}}^{1 / 2}$ as being equal to 0.78 .

As can be seen from Figure 4, the comparison made between the cyclic voltamograms of $\left[\mathrm{Fe}(\mathrm{CN})_{5^{-}}\right.$ $\left(4,4^{\prime}-\text { bpy) }\right]^{3-}$ (curve B) and $\left[\mathrm{Fe}(\mathrm{CN})_{5}\left(\mathrm{NH}_{3}\right)\right]^{3-}$ (curve $\mathrm{C}$ ), both of them recorded in "middle phase", put in evidence the influence of the hydrophobic (lipophilic) character of 4,4'-bipyridine ligand on the distribution of the complex ion between the "microscopic aqueous phase" and "water phase" even if both of them are aqueous in nature. The complex ion distribution is favoured, in $\left[\mathrm{Fe}(\mathrm{CN})_{5}\left(4,4^{\prime}-\text { bpy }\right)\right]^{3-}$ case, by the more favourable 


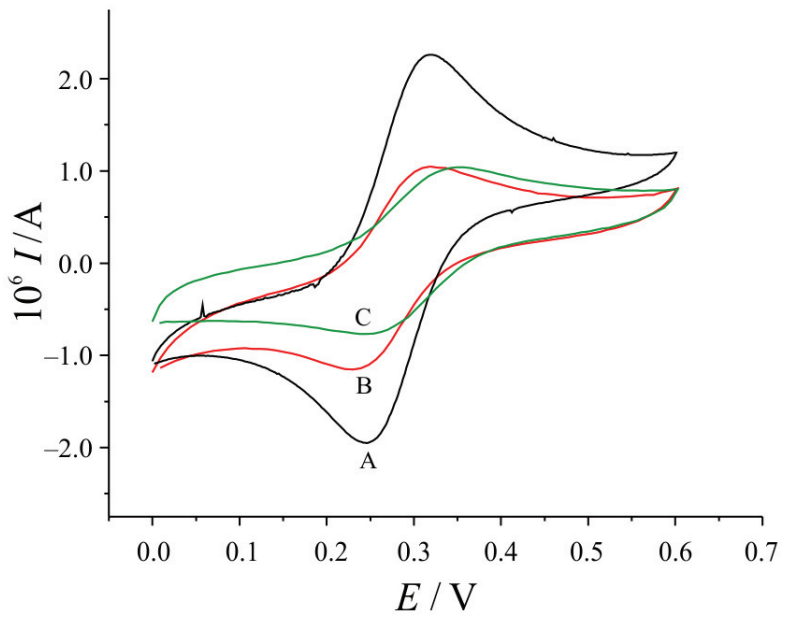

Figure 4. The cyclic voltamograms at $v=20 \mathrm{mV} \mathrm{s}^{-1}$ of $\mathrm{K}_{4}[\mathrm{Fe}$ $\left.(\mathrm{CN})_{6}\right](\mathrm{A}), \mathrm{Na}_{3}\left[\mathrm{Fe}(\mathrm{CN})_{5}\left(4,4^{\prime}-\right.\right.$ bpy $\left.)\right]$ (B) and $\mathrm{Na}_{3}\left[\mathrm{Fe}(\mathrm{CN})_{5}\right.$ $\left(\mathrm{NH}_{3}\right)$ ] $(\mathrm{C})$ with all electrodes in "middle phase", for $1 \mathrm{mmol}$ $\mathrm{dm}^{-3}$ initial concentration referred to initial water amount.

interaction of the complex ion containing the organic ligand with "microscopic organic phase". This result is also in very good agreement with the previous conclusion regarding the cyclic voltamograms in Figure 3a. On the contrary, for the latter complex ion, $\left[\mathrm{Fe}(\mathrm{CN})_{5}\left(\mathrm{NH}_{3}\right)\right]^{3-}$, containing a hydrophilic ligand as ammonia, the cyclic voltamogram in Figure 4 (curve C) shows both anodic and cathodic peak currents smaller than for the former complex (curve B).

Taking into account the behaviour illustrated in Figure $3 b$, two concluding remarks have to be drawn: (1) for equal concentrations and equal diffusion coefficients of $\left[\mathrm{Fe}(\mathrm{CN})_{5}\left(\mathrm{NH}_{3}\right)\right]^{3-}$ complex ion in the two aqueous phases, it results that less than a half of the active electrode surface is concerned to the electrode reaction in "middle phase". In other words one can say that less than a half of this electrode surface is in direct contact with the "microscopic aqueous phase". This is somewhat at variance with the ratio of the two volumes of the "toluene phase" and "water phase" of the threephase system. In consequence, (2) considering that half of the working electrode surface is concerned to the electrode reaction (or, alternatively, is in direct contact with the "microscopic aqueous phase"), it results that either the concentration or the diffusion coefficient or even both of them must be higher in the "water phase" than in "microscopic aqueous phase".

A comparison of the cyclic voltamograms recorded with all three electrodes in "middle phase" (see Figure 4) of the two complex ions considered in this paper with the common $\left[\mathrm{Fe}(\mathrm{CN})_{6}\right]^{4-}\left(E_{\mathrm{pa}}=321 \mathrm{mV}, \Delta E_{\mathrm{p}}=71\right.$ $\mathrm{mV}, E_{1 / 2}=284 \mathrm{mV}$ ) (curve A) complex ion shows: (1) for $\left[\mathrm{Fe}(\mathrm{CN})_{5}\left(4,4^{\prime}-\text { bpy }\right)\right]^{3-}\left(E_{\mathrm{pa}}=333 \mathrm{mV}, \Delta E_{\mathrm{p}}=76 \mathrm{mV}\right.$, $E_{1 / 2}=295 \mathrm{mV}$ ) (curve B) an anodic shift and (2) for $\left[\mathrm{Fe}(\mathrm{CN})_{5}\left(\mathrm{NH}_{3}\right)\right]^{3-}\left(E_{\mathrm{pa}}=310 \mathrm{mV}, \Delta E_{\mathrm{p}}=79 \mathrm{mV}, E_{1 / 2}=\right.$
$275 \mathrm{mV}$ ) (curve C) a cathodic shift of the half-wave potential in comparison with $\left[\mathrm{Fe}(\mathrm{CN})_{6}\right]^{4-}$. So that, the complex ion redox reactivity is displayed in the following order according to their increasing oxidation potential or half-wave potential: $\left[\mathrm{Fe}(\mathrm{CN})_{5}\left(\mathrm{NH}_{3}\right)\right]^{3-}<$ $\left[\mathrm{Fe}(\mathrm{CN})_{6}\right]^{4-}<\left[\mathrm{Fe}(\mathrm{CN})_{5}\left(4,4^{\prime}-\text { bpy }\right)\right]^{3-}$. Looking at their peak currents (anodic or cathodic), and the shape of the cyclic voltamograms, it seems that a decrease of the reversibility occurs from $\left[\mathrm{Fe}(\mathrm{CN})_{6}\right]^{4-}\left(I_{\mathrm{pa}}=2.26 \mu \mathrm{A}\right)$ to $\left[\mathrm{Fe}(\mathrm{CN})_{5}\left(4,4^{\prime}-\mathrm{bpy}\right)\right]^{3-}\left(I_{\mathrm{pa}}=1.04 \mu \mathrm{A}\right)$ and, finally, to $\left[\mathrm{Fe}(\mathrm{CN})_{5}\left(\mathrm{NH}_{3}\right)\right]^{3-}\left(I_{\mathrm{pa}}=1.04 \mu \mathrm{A}\right)$ due to the decreasing current peak values in the same order.

\section{CONCLUSION}

The two redox species (reduced component of the redox couples) give rise to almost fast (reversible) electrochemistry both in the "middle phase" and in the "water phase". For the complex containing as coligand 4,4'bipyridine, a contribution of absorption of the electroactive species was put in evidence. The $\mathrm{CV}$ is able to notice a preponderant distribution of $\left[\mathrm{Fe}(\mathrm{CN})_{5}\left(4,4^{\prime}\right.\right.$ bpy) $]^{3-}$ species in the "microscopic aqueous phase" vs. "water phase". This preferential distribution could be ascribed to the presence of much more lipophilic (the HLB is shifted towards the lipophilic direction) 4,4'-bipyridine as ligand. On the contrary, the $\left[\mathrm{Fe}(\mathrm{CN})_{5}\left(\mathrm{NH}_{3}\right)\right]^{3-}$ species behave as expected due to the more hydrophilic (the HLB is shifted towards the hydrophilic direction) ammonia as ligand. The product $A_{\varphi} D_{\varphi}^{1 / 2} c_{\varphi}$ ( $\varphi$ being the phase to which the electroactive species belongs) or ratio of this kind of products, might be estimated by using Randles-Sevcik equations either by plotting $I_{\mathrm{p}} v s . v^{1 / 2}$ or by using the slopes of such sort of plots. With proper assumptions, one may predict about the distribution of some electroactive species between the "microscopic aqueous phase" and "water phase" for more hydrophilic species, or one may predict on the value of its diffusion coefficient in "middle phase" in comparison with that in "water phase".

Based on their half-wave potentials an order of redox reactivity is also established: $\left[\mathrm{Fe}(\mathrm{CN})_{5^{-}}\right.$ $\left(4,4^{\prime}-\right.$ bpy $\left.)\right]^{3-}$ is more powerful oxidant and $\left[\mathrm{Fe}(\mathrm{CN})_{5^{-}}\right.$ $\left.\left(\mathrm{NH}_{3}\right)\right]^{3-}$ is more powerful reductant in the three cyanoferrate(II) series $\left[\mathrm{Fe}(\mathrm{CN})_{5}\left(4,4^{\prime}-\mathrm{bpy}\right)\right]^{3-},\left[\mathrm{Fe}(\mathrm{CN})_{6}\right]^{4-}$ and $\left[\mathrm{Fe}(\mathrm{CN})_{5}\left(\mathrm{NH}_{3}\right)\right]^{3-}$, but the difference between the halfwave potential is not too important.

From electrochemical data, especially from the peak currents flowing for each redox species through the working electrode, and taking also into consideration the shape of the cyclic voltamograms, a decrease of reversibility was also established from $\left[\mathrm{Fe}(\mathrm{CN})_{6}\right]^{4}$ (the most reversible) to $\left[\mathrm{Fe}(\mathrm{CN})_{5}\left(4,4^{\prime}-\mathrm{bpy}\right)\right]^{3-}$ and, finally, to $\left[\mathrm{Fe}(\mathrm{CN})_{5}\left(\mathrm{NH}_{3}\right)\right]^{3-}$ (the least reversible). 


\section{REFERENCES}

1. K. Shinoda and H. Kuneida, J. Colloid Interface Sci. 42 (1973) 381-387.

2. H.Saito and K. C. Shinoda, J. Colloid Interface Sci. 32 (1970) 647-651.

3. K. Shinoda and H. Arai, J. Phys. Chem. 68 (1964) 3485-3490.

4. M. T. Clarkson, D. Beaglehole, and P. T. Callaghan, Phys. Rev. Lett. 54 (1985) 1722-1724.

5. L. E. Scriven, Nature 263 (1976) 123-125.

6. M. O. Iwunze, A. Sucheta, and J. F. Rusling, Anal. Chem. 62 (1990) 644-649.

7. P. G. Gennes and C. Taupin, J. Phys. Chem. 86 (1982) 2294-2304.

8. B. A. Mackey and J. Texter, Electrochemistry in colloid and dispersions, Wiley-VCH, New York, 1991.

9. P. Guering and B. Lindman, Langmuir 1 (1985) 464- 468.

10. M. Kunitache, S. Murasaki, S. Yoshitake, A. Ohira, I. Taniguchi, M. Sakato, and T. Nishimi, Chem. Lett. 10 (2005) 1338-1339.
11. J. Santhanalakshmi and G. Vijayalakshmi, Langmuir 13 (1997) 3915-3920.

12. Z. Yang, J. Zhao, L. Gao, T. Wang, Q. Cao, N. Zhang, and Z. Yang, Anal. Lett. 39 (2006) 1801-1808.

13. D. Bala, P. Dasu and C. Mihailciuc, Rev. Roum. Chim. 56 (2011) 1129-1136.

14. G. Brauer, Handbuch der Präparativen Anorganischen Chemie, Ferdinand Enke, Stuttgart, 1978, vol. 3, 1657.

15. C. D. Ene, A. Lungu, C. Mihailciuc, M. Hillebrand, C. RuizPerez, and M. Andruh, Polyhedron 31 (2012) 539-547.

16. F. Scholz (Ed.), Electroanalytical Methods, Guide to Experiments and Applications (Ch. II.1 Cyclic Voltammetry, F. Marken, A. Neudeck, A. M. Bond), Springer-Verlag, Berlin Heidelberg New York, 2002, 67.

17. S. Yoshitake, A. Ohira, M. Tominaga, T. Nishimi, M. Sakata, C. Hirayama, and M. Kunitake, Chem. Lett. 3 (2002) 360-361.

18. C. Mo, M. Zhong, and Q. Zhong, J. Electroanal. Chem. 493 (2000) 100-107. 